\title{
In pursuit of objective dry eye screening clinical techniques
}

\author{
Anastasios John Kanellopoulos ${ }^{1,2^{*}}$ and George Asimellis ${ }^{1}$
}

\begin{abstract}
Dry eye is a multifactorial, progressive, and chronic disease of the tears and ocular surface. The disease is multi-factorial and has intermittent symptoms. Discomfort, visual disturbance, tear film instability with potential damage to the ocular surface, and increased tear film osmolarity are known associates.

Dry eye is a common clinical problem for eye-care providers worldwide and there is a large number of clinical investigative techniques for the evaluation of dry eye. Despite this, however, there is no globally accepted guideline for dry eye diagnosis and none of the available tests may hold the title of the 'gold standard'. The majority of the techniques involved in the diagnosis of the disease, particularly for its early stages, has a large degree of subjectivity.

The purpose of this article is to review existing dry eye investigative techniques and to present a new objective dry eye screening technique based on optical coherence tomography.
\end{abstract}

Keywords: Dry eye, Shrimer's test, TBUT test, Inflammation, OCT, Epithelial thickness, Anterior-segment

\section{Background}

Dry eye disease [1] is responsible for major population morbidity and considerable economic impact in terms of both direct and indirect costs [2] because of the disease's progressive nature and the significant toll on quality of life [3]. In addition, it may present major challenges in a refractive surgery candidate assessment [4]. Its condition may range from mild/episodic to severe/chronic: the disorder can be manifested with many symptoms including visual disturbance (blurred and fluctuating vision), foreign-body sensation and eye discomfort (patient-reported), irritation, ocular surface inflammation, redness, excess tearing, and photosensitivity [5-9].

Contributing factors to dry eye may be classified as ocular, medical, pharmaceutical, iatrogenic, environmental, and contact lens wear [10].

Ocular conditions include eyelid (blepharitis) and ocular surface inflammation, and chemical burns. Medical conditions include Sjögren's syndrome, [11] vitamin-A and omega-3 fatty acid deficiency, rheumatoid arthritis and other rheumatologic diseases, as well as diabetes

\footnotetext{
* Correspondence: ajk@brilliantvision.com

${ }^{1}$ Laservision.gr Clinical and Research Eye Institute, 17 Tsocha Street, Athens 11521, Greece

2Department of Ophthalmology, New York University Medical School, New York, NY, USA
}

(c) 2016 Kanellopoulos and Asimellis. Open Access This article is distributed under the terms of the Creative Commons Attribution 4.0 International License (http://creativecommons.org/licenses/by/4.0/), which permits unrestricted use, distribution, and reproduction in any medium, provided you give appropriate credit to the original author(s) and the source, provide a link to the Creative Commons license, and indicate if changes were made. The Creative Commons Public Domain Dedication waiver (http://creativecommons.org/publicdomain/zero/1.0/) applies to the data made available in this article, unless otherwise stated. and thyroid problems. Reactions to certain medications such as antihistamines, diuretics, sleeping pills, decongestants, blood-pressure medications and antidepressants, postmenopausal estrogen therapy medications, and isotretinoin-type drugs for acne treatment, may contribute in their capacity to impact tear production [12]. Iatrogenic conditions include eyelid/facial surgery and corneal refractive surgery. Specific to laser in situ keratomileusis (LASIK), although pre-existing dry eye may be subclinical, a sizable portion of LASIK patients may develop reduced basal tear flow, [13] attributed to surgical severing of the nerves by the creation of the LASIK flap, $[14,15]$ and/or by the excimer laser ablation [16]. Environmental conditions include aridity, cold/windy air, and repetitive occupational tasks that require increased concentration that affect blinking [17].

\section{Review}

Clinical investigative techniques for the evaluation of dry eye

The importance of proper and timely distinction between healthy and affected eyes is unquestionable [18-20].

There is a large number of clinical investigative techniques for the evaluation of dry eye. The current options include slit-lamp observations, tear film stability 
assessment (invasive/non-invasive tear-film breakup time (TBUT) measurement, tear film interferometry), [21] tear secretion assessment tests (Schirmer lacrimation with or without anesthesia, thread methods), tear clearance assessment (fluorescein clearance test, tear function index, fluorophotometry), [22] ocular surface damage assessment (corneal and conjunctival, rose Bengal, lissamine green staining, cytology), [23] lipid layer assessment (precorneal/meibomian grading), [24, 25] tear osmolarity tests, [26-29] and patient subjective symptom questionnaires [30].

However, the problem of definite dry eye assessment is bedeviled by many parameters and several aspects may make a safe diagnosis challenging particularly in the early or mild stages. Poor diagnostic test repeatability [31] that is manifested as significant false-positive/negative rates, [32] broad range of variability, wide range of sensitivity and specificity, and dependence on clinical conditions [33] are some of the reasons cited [34].

We also have to consider the multi-factorial nature of the disease and the intermittency of the symptoms: there is a continuum of susceptibility and possible overlay/ interference of the presented symptoms with other ocular irritations and environmental influences [35]. Seasonal and diurnal variations are also factors that may affect symptoms [36].

Another aspect is that among the prevailing investigative techniques such as Schrimer's lacrimation and TBUT tests, there are examiner subjectivity, [37] external stimuli influence, [38] and accurate documentation difficulty [39]. The same is true for investigative techniques based on patient-reported symptom questionnaires [40-42]. Published evidence suggest that clinical dry eye symptoms alone may be insufficient for proper diagnosis of the disease $[43,44]$.

Adding to the challenge is the fact that despite the existence of several dry eye scoring systems, [45] there is no globally-accepted guideline for dry eye diagnosis and none of the available tests may hold the title of the 'gold standard' [46]. With no widely accepted gold standard against which to measure the tests, manipulation of the diagnostic criteria used for the standard can affect the reported sensitivity of new tests.

The other end of the problem is that there is no established clear-cut threshold for early-stage dry eye definite assessment. This aspect hinders the adoption of cut-off values for any traditional metric. The problem of establishing precise cut offs between normal and dry eye patients lies less with the test and more with the understanding that like almost all diagnostic tests, not every individual has the same threshold for revealing disease but rather there is a range in the population; one that the clinician should have a clear understanding of in regards to disease development. Notwithstanding that, cut offs with highly useful clinical utility are available and supplementary values e.g., inter-eye differences in tear osmolarity, add to the specificity of the tests.

There is a critical need therefore, for a consensus of newer/updated investigative techniques and metrics that will better reflect the differential discrimination of the disease [33].

\section{In search for an objective dry eye assessment technique}

A novel objective investigative technique for dry eye screening that has been recently proposed by our team is the objective evaluation of epithelial thickness by anterior-segment optical coherence tomography (ASOCT) [47]. Specifically, overall epithelial thickness may reflect conditions such as moderate or even subclinical dry eye and may aid in the timely diagnosis.

\section{Why epithelium?}

It has been established that the epithelial layer thickness and morphology may be influenced by hypoxia, [48] contact lens wear, $[49,50]$ corneal ectasia, [51] corneal cross-linking, [52] and ocular surgery such as clearcornea incision cataract removal, [53] corneal lamellar surgery, [54] and corneal refractive surgery $[55,56]$.

Epithelial thickening may be an alarming indication for corneal abnormality. In a previous investigation of the three-dimensional epithelial thickness in keratoconic eyes, [51] we identified an overall thicker epithelium that might be a result of a reactive process; the epithelium appears to thicken in less 'rigid' corneas due to being more susceptible to mechanical variations produced by one or a combination of factors including eye rubbing and increased blinking mechanism [57].

Regarding dry eye, advanced stages may be reflected as morphological epithelial damage [58]. Increased epithelial thickness has been associated with dry eye in a rat model, and has been associated with the inflammatory process [59]. Atopic keratoconjunctivitis has been associated with significant alterations of the basal epithelium, and subbasal and stromal corneal nerves, related to the changes in tear functions and corneal sensitivity [60]. Studies with scanning microscopy have identified altered central epithelial thickness in dry eyes [61] or epithelial thickness irregularities in cases with Sjögren's syndrome $[62,63]$. In a confocal laser scanning microscopy study, [64] the mean superficial and intermediate epithelial cell densities in the central cornea in the dry eye groups were significantly lower than in normal participants. Dry eye corneas showed significant corneal epithelial alterations, presumably due to increased desquamation of the superficial cell layer. 


\section{The case for OCT}

In the past, the available investigating and clinical evaluation modalities for the purpose of epithelial thickness imaging have been high-frequency ultrasound (HFUBM), time-domain OCT, and confocal microscopy through focusing (CMTF) [65]. None of these were fully clinically applicable and/or had a commercially available model for this specific use. For example, HF-UBM employs fluid coupling, which explains why we have not identified any reports on dry eye and HF-UBM measurements. CMTF requires instrument interface contact with the cornea, and had been restricted in this application due to the degraded precision by eye movement during the long acquisition time. Other available techniques are either invasive or require contact between the probe and the ocular surface, and thus cannot provide precise in vivo measurement of the entire epithelial thickness.

OCT has the advantage of the ease of in vivo noncontact application and speed of optical imaging [66]. Until recently, however, its application in epithelial thickness imaging involved either investigator-modified software/hardware [67-69] or caliper software measurement techniques $[58,70]$ (for example, by manually placing cursors to measure epithelial thickness in each location).

The novelty offered by the Fourier-domain anteriorsegment OCT system RtVue-100 (Optovue Inc., Fremont, $\mathrm{CA}$ ) is that it is the first OCT system that incorporates epithelial thickness maps (extending, currently up to 6$\mathrm{mm}$ diameter) analysis. In each meridional scan, the system software automatically identifies the air-tear film interface and the epithelium-Bowman layer interface. The report then provides the pachymetry maps of both total corneal and corneal epithelial thickness shown in Fig. 1. This screening examination may be included in the routine screening protocol of all patients [71]. Thus, this examination potentially presents a practical clinical tool for qualitative (by evaluation of the three-dimensional epithelial thickness mapping) and quantitative epithelium evaluation (data for absolute average, central, and peripheral epithelial thickness measurements). This investigation revealed that the measurement repeatability was of the order of $1 \mu \mathrm{m}$, and the topographic thickness variability was found to be of the order of $0.25 \mu \mathrm{m}$ [71]. There were some epithelial thickness differences between male and female groups (Female group average $52.58 \pm 3.19 \mu \mathrm{m}$, Male group average $54.10 \pm 3.34 \mu \mathrm{m}$ ). Topographic thickness variability between the two groups did not differ at the 0.05 level of significance $(p=0.173)$. Age also appeared to be an influencing factor: epithelial thickness for the younger group was $52.95 \pm 3.44 \mu \mathrm{m}$, while for the older group was $53.64 \pm 3.21 \mu \mathrm{m}$ (not statistically significant, however).

OCT epithelial thickness mapping with this system has recently gained clinical impetus and research interest by other teams as well $[72,73]$.

\section{A new proposition}

In pursuit of an objective, repeatable, and quantitative clinical test that may aid in the differential diagnosis of dry eye, we introduced the concept of corneal epithelial thickness as a possible tool in dry eye assessment, and reported initial clinical results regarding threedimensional corneal epithelial thickness mapping in dry eye corneas employing the RtVue-100 OCT system [47].

Our study suggested that there is a statistically significant thicker corneal epithelium in mid-aged female population diagnosed with moderate dry eye in comparison to an age-matched control population.

We believe that the clinical difference observed might play a role in routine screening and treatment assessment, which may precede the specific dry eye measurements that may or may not be part of a standard screening protocol. The findings reported herein may also be very useful in the screening of refractive surgery candidates, and even in the assessment of post-operative iatrogenically induced dry eye [13].

In a recent study by Cui et al. [74] central epithelium thickness in dry eyes, measured by the same Fourier-domain OCT, was found to be significantly thinner than that in normal eyes. Notably, the thinner tendency was larger in the more severe stages. Our team has also identified thinning and increased topographic variability of the epithelium in older agepatients [71]. It is possible that in advanced stages in older-age patients, the chronic insidious injury by a deficient tear film or the destruction of stem cells at the limbus may be likely causes for epithelial thinning. In addition, we emphasize that one should not only take into account the central epithelial thickness, but also information deriving from the overall epithelial thickness, as due to immune and angiogenic privilege, central cornea may be less sensitive to inflammation than the limbus and conjunctiva [75].

Further cell morphology studies in epithelial thickness associated with dry eye i.e., with confocal microscopy, may be warranted to differentiate these noted differences, which may include epithelial hypertrophy/ hyperplasia, swollen cells, and/or increase in the number of cellular layers.

The anticipated clinical ramifications of the application are prospectively very positive since this screening indicator is based on a commercially available instrument that can easily be integrated into daily clinical practice and with increasing clinical screening potential.

\section{Our investigation}

We conducted a comparative retrospective investigation forming two groups. The 'control', group A ( $\mathrm{n}=70$ eyes, 35 patients), consisted of ambulatory female patients 




b
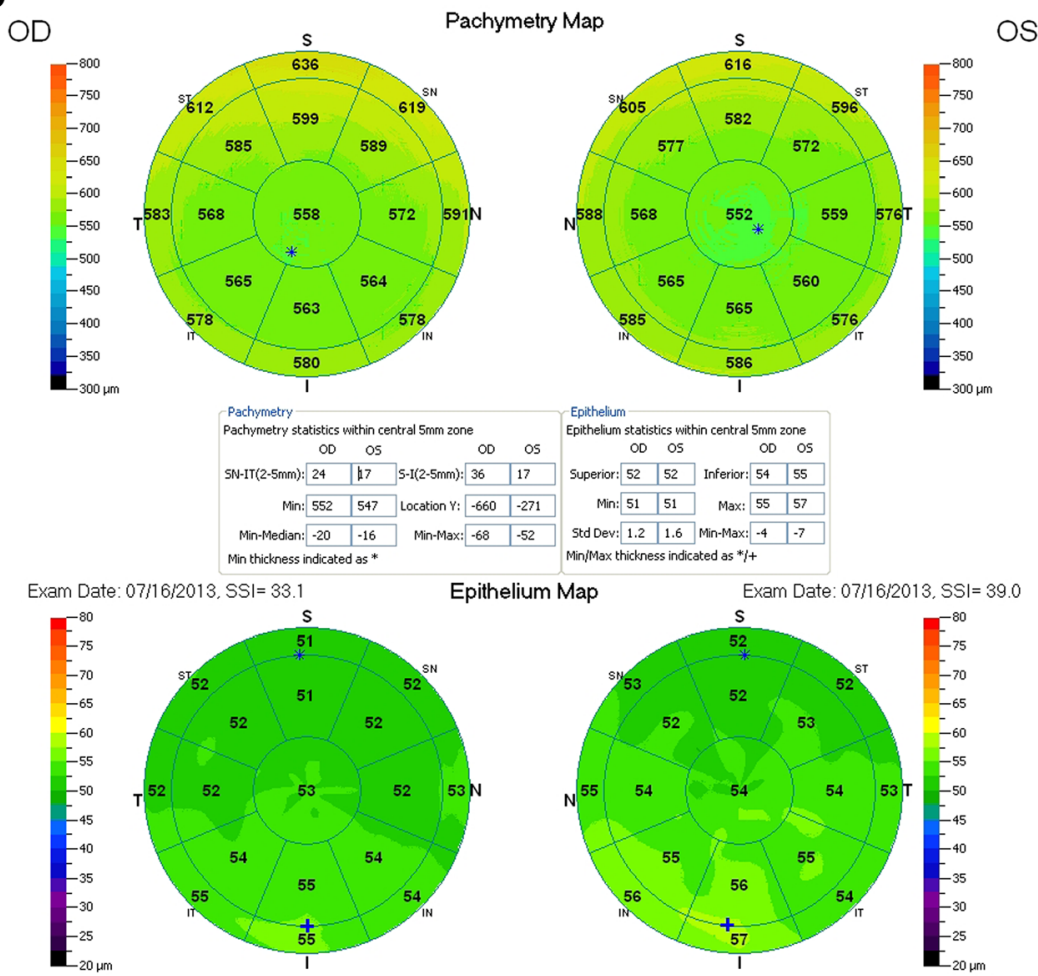

Fig. 1 Representative thickness maps provided by the OCT system report, including total corneal, and corneal epithelium thickness maps. Top-a is a typical example from a 'normal-group' patient, while bottom-b from a dry-eye patient 
with unoperated, normal eyes with no ocular pathology other than refractive error, and no dry eye condition, confirmed by a complete ocular clinical evaluation. The 'dry eye', group B ( $\mathrm{n}=70$ eyes, 35 patients), consisted of female patients with clinically confirmed dry eye, otherwise unoperated and with no other ocular pathology save for possible refractive error. All patients signed an informed consent form, releasing anonymous data evaluation for scientific purposes.

Both groups consisted of female patients with dry eye because they compose 10:1 compared to males as observed in our clinical practice (unpublished data). Dry eye was diagnosed via TBUT measurement (dry eye considered if under $5 \mathrm{~s}$ ) and Schirmer basic lacrimation test (dry eye considered if under $5 \mathrm{~mm}$ ). Exclusion criteria were anterior basement membrane and other corneal dystrophies, and/or rheumatic diseases. No patient with reported previous use of contact lens nor with recent dispensing of artificial tear drops was enrolled in this study in either group.

For each eye we measured and analyzed statistically within the central $5 \mathrm{~mm}$ zone the average, superior, and inferior epithelial thickness, as well as topographic thickness variability, as reported by the standard deviation of the seventeen (17) segments (shown in Fig. 1) local thickness measurements. Average epithelium thickness was computed for each case within the $5 \mathrm{~mm}$ zone as the average of the seventeen segments local thickness measurements. Examples of such maps from each group are shown in Fig. 1.

The study suggested an overall thicker epithelium in the group of dry eye female patients, and specifically, a statistically different epithelial thickness between the dry eye and control groups. The differences (average in dry to normal eyes) ranged, for the central thickness by +6.5 $\mu \mathrm{m}$ and for the average thickness by $+6.2 \mu \mathrm{m}$. Details are reported in [47] and [76].

Despite the overlap in the thickness between control and dry eye epithelial layer thickness, these differences were statistically significant. Moreover, these differences were larger than the repeatability measurement fluctuations. In a recent evaluation [71] of a large population of healthy eyes (373 cases), average epithelial thickness repeatability was at $0.8 \pm 0.7 \mu \mathrm{m}$.

Increased epithelial thickness may also be encountered in ectatic corneas. The differentiating factor between the thicker 'dry eye' and the thicker keratoconic epithelium lies in the topographic thickness variability. In normal eyes, we measured an average of $1.8 \pm 1.1 \mu \mathrm{m}$ [71]. In the dry eye study, the topographic thickness variability was $2.5 \pm 1.5 \mu \mathrm{m}$, slightly larger than in the 'healthy eye' population, while in the keratoconic study thickness variability was found to be significantly larger (up to $10.3 \mu \mathrm{m})$, thus enabling differentiation.
In this study, the specific imaging with the RtVue system might also influence dry eye epithelial measurements by the AS-OCT device. In a previous OCT study of epithelial thickness by Francoz et al. [58] with a different instrumentation, difference between central epithelial thickness between middle-aged normal $(48.8 \pm 3.0 \mu \mathrm{m})$ and dry eye population $(49.0 \pm 4.1 \mu \mathrm{m})$ was much smaller. This can be attributed to investigative differences: in the current study, average epithelial thickness was accurately reported on the select meridian scans and interpolated on the space between while the study by Francoz et al. implemented manual position on select scanned meridians to measure epithelial thickness. The different geographical locale might also be a factor.

\section{Conclusions}

Among the newly emerging dry eye testing options, tear film osmolarity may be considered an objective technique. The test employs a disposable test chip (TearLab Corp., San Diego, CA) that collects a small $(50 \mathrm{~nL})$ tear sample from the lower meniscus [77]. Analysis is based on electrical impedance (milliosmoles per liter) of the tear sample [28].

Newly emerging techniques that may be considered are thermography, [78] a technique incorporated in a clinical autorefractor/keratometer (RC 5000; Tomey Corporation, Nagoya, Japan), as well as the noninvasive tear breakup time recorded and digital measurement with an optional feature of a corneal Placido-ring topographer (Keratograph 5M; Oculus Optikgeräte GmbH, Wetzlar, Germany) [79].

Sensory testing could also be useful diagnostically, notwithstanding issues relating to altered corneal epithelial barrier function [80, 81].

We introduced and presented a novel dry eye screening technique based on a clinical OCT device. The screening is part of our established protocol not only for dry eye, but also for general evaluation of the cornea; thus the potential for dry eye alert comes as a collateral benefit. We emphasize that the clinical diagnostic capacity of the increased overall epithelial thickness that we introduced has importance for early-stage, subclinical dry eye, and not severe dry eye, for which many other techniques may offer a more concrete diagnosis.

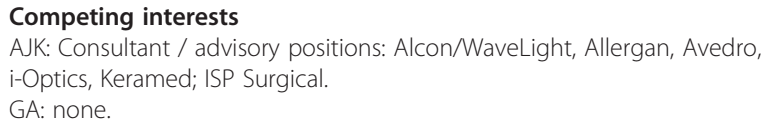

\section{Authors' contributions}

Design and conduct of the study (AJK, GA); collection (GA), management $(A J K)$, analysis (GA, AJK), interpretation of the data (AJK, GA); manuscript preparation (GA), manuscript review (AJK, GA). All authors read and approved the final manuscript. 


\section{Received: 27 October 2015 Accepted: 22 December 2015}

\section{Published online: 18 January 2016}

\section{References}

1. (no authors listed) The definition and classification of dry eye disease: report of the Definition and Classification Subcommittee of the International Dry Eye WorkShop (2007). Ocul Surf. 2007:5:75-92.

2. Pflugfelder SC. Prevalence, burden, and pharmacoeconomics of dry eye disease. Am J Manag Care. 2008;14 Suppl 3:S102-6.

3. Mertzanis P, Abetz L, Rajagopalan K, Espindle D, Chalmers R, Snyder C, et al. The relative burden of dry eye in patients' lives: comparisons to a U.S. normative sample. Invest Ophthalmol Vis Sci. 2005;46:46-50.

4. Li M, Gong L, Chapin WJ, Zhu M. Assessment of vision-related quality of life in dry eye patients. Invest Ophthalmol Vis Sci. 2012;53:5722-7.

5. Turaka K, Hammersmith KM, Nagra PK, Nagra PK, Rapuano CJ. Dry eye syndrome in aromatase inhibitor users. Clin Experiment Ophthalmol. 2013;41:239-43.

6. O'Brien PD, Collum LM. Dry eye: diagnosis and current treatment strategies. Curr Allergy Asthma Rep. 2004;4:314-9.

7. Portello JK, Rosenfield M, Bababekova Y, Estrada JM, Leon A. Computerrelated visual symptoms in office workers. Ophthalmic Physiol Opt. 2012;32:375-82.

8. Torricelli AA, Novaes P, Matsuda M, Braga A, Saldiva PH, Alves MR, et al. Correlation between signs and symptoms of ocular surface dysfunction and tear osmolarity with ambient levels of air pollution in a large metropolitan area. Cornea. 2013;32:e11-5.

9. Hirayama M, Murat D, Liu Y, Kojima T, Kawakita T, Tsubota K. Efficacy of a novel moist cool air device in office workers with dry eye disease. Acta Ophthalmol. 2013;91(8):756-62. doi:10.1111/j.1755-3768.2012.02485.x.

10. Doughty MJ, Fonn D, Richter D, Simpson T, Caffery B, Gordon K. A patient questionnaire approach to estimating the prevalence of dry eye symptoms in patients presenting to optometric practices across Canada. Optom Vis Sci. 1997;74:624-31.

11. Foulks GN, Forstot SL, Donshik PC, Forstot JZ, Goldstein MH, Lemp MA, et al. Clinical guidelines for management of dry eye associated with Sjögren disease. Ocul Surf. 2015;13:118-32.

12. Colligris B, Alkozi HA, Pintor J. Recent developments on dry eye disease treatment compounds. Saudi J Ophthalmol. 2014;28:19-30.

13. Wilson SE. Laser in situ keratomileusis-induced (presumed) neurotrophic epitheliopathy. Ophthalmology. 2001;108:1082-7.

14. Sun CC, Chang CK, Ma DH, Lin YF, Chen KJ, Sun MH, et al. Dry eye after LASIK with a femtosecond laser or a mechanical microkeratome. Optom Vis Sci. 2013;90:1048-56.

15. Toda I. LASIK and the ocular surface. Cornea. 2008;27 Suppl 1:S70-6.

16. Azuma M, Yabuta C, Fraunfelder FW, Shearer TR. Dry eye in LASIK patients. BMC Res Notes. 2014;7:420

17. Fenga C, Aragona P, Di Nola C, Spinella R. Comparison of ocular surface disease index and tear osmolarity as markers of ocular surface dysfunction in video terminal display workers. Am J Ophthalmol. 2014;158:41-8.e2.

18. Williamson JF, Huynh K, Weaver MA, Davis RM. Perceptions of dry eye disease management in current clinical practice. Eye Contact Lens. 2014;40:111-5

19. Nichols KK, Nichols JJ, Zadnik K. Frequency of dry eye diagnostic test procedures used in various modes of ophthalmic practice. Cornea. 2000;19:477-82.

20. van Tilborg MM, Murphy PJ, Evans KS. Agreement in dry eye management between optometrists and general practitioners in primary health care in the Netherlands. Cont Lens Anterior Eye. 2015:38(4):283-93.

21. Goto T, Zheng X, Klyce SD, Kataoka H, Uno T, Karon M, et al. A new method for tear film stability analysis using videokeratography. Am J Ophthalmol. 2003:135:607-12.

22. Afonso AA, Monroy D, Stern ME, Feuer WJ, Tseng SC, Pflugfelder SC Correlation of tear fluorescein clearance and Schirmer test scores with ocular irritation symptoms. Ophthalmology. 1999;106:803-10.

23. Brignole F, Ott AC, Warnet JM, Baudouin C. Flow cytometry in conjunctival impression cytology: a new tool for exploring ocular surface pathologies. Exp Eye Res. 2004;78:473-81.

24. Yanga Z, San CTL, Tong L. Intra-observer and inter-observer repeatability of ocular surface interferometer in measuring lipid layer thickness. BMC Ophthalmol. 2015;15:53.
25. Robin JB, Jester JV, Nobe J, Nicolaides N, Smith RE. In vivo transillumination biomicroscopy and photography of meibomian gland dysfunction. Ophthalmology. 1985;92:1423-6.

26. Tomlinson A, McCann LC, Pearce El. Comparison of human tear film osmolarity measured by electrical impedance and freezing point depression techniques. Cornea. 2010:29:1036-41.

27. Bunya VY, Fuerst NM, Pistilli M, McCabe BE, Salvo R, Macchi I, et al. Variability of tear osmolarity in patients with dry eye. JAMA Ophthalmol. 2015;133(6): 662-7. doi:10.1001/jamaophthalmol.2015.0429.

28. Lemp MA, Bron AJ, Baudouin C, Benítez Del Castillo JM, Geffen D, Tauber J, et al. Tear osmolarity in the diagnosis and management of dry eye disease. Am J Ophthalmol. 2011;151:792-8.e1.

29. Versura P, Profazio V, Campos EC. Performance of tear osmolarity compared to previous diagnostic tests for dry eye diseases. Curr Eye Res. 2010;35:553-64.

30. Alves M, Reinach PS, Paula JS, Vellasco e Cruz AA, Bachette L, Faustino J, et al. Comparison of diagnostic tests in distinct well-defined conditions related to dry eye disease. PLoS One. 2014;9(5):e97921.

31. Sullivan BD, Crews LA, Sönmez B, de la Paz MF, Comert E, Charoenrook V, et al. Clinical utility of objective tests for dry eye disease: variability over time and implications for clinical trials and disease management. Cornea. 2012:31:1000-8.

32. Tomlinson A, Khanal S, Ramaesh K, Diaper C, McFadyen A. Tear film osmolarity: determination of a referent for dry eye diagnosis. Invest Ophthalmol Vis Sci. 2006:47:4309-15.

33. Savini G, Prabhawasat P, Kojima T, Grueterich M, Espana E, Goto E. The challenge of dry eye diagnosis. Clin Ophthalmol. 2008;2:31-55.

34. Korb DR. Survey of preferred tests for the diagnosis of the tear film and dry eye. Cornea. 2000;19:483-6.

35. Pflugfelder SC, Tseng SC, Sanabria O, Kell H, Garcia CG, Felix C, et al. Evaluation of subjective assessments and objective diagnostic tests for diagnosing tear-film disorders known to cause ocular irritation. Cornea. 1998;17:38-56

36. McGinnigle S, Naroo SA, Eperjesi F. Evaluation of dry eye. Surv Ophthalmol. 2012;57:293-316.

37. Cho P, Yap M. Schirmer test. I. A review. Optom Vis Sci. 1993:70:152-6.

38. Yokoi N, Komuro A. Non-invasive methods of assessing the tear film. Exp Eye Res. 2004:78:399-407.

39. Foulks GN. Challenges and pitfalls in clinical trials of treatments for dry eye. Ocul Surf. 2003:1:20-30.

40. Simpson TL, Situ P, Jones LW, Fonn D. Dry eye symptoms assessed by four questionnaires. Optom Vis Sci. 2008;85:692-9.

41. Dogru M, Nakamura M, Shimazaki J, Tsubota K. Changing trends in the treatment of dry-eye disease. Expert Opin Investig Drugs. 2013;22:1581-601.

42. Schiffman RM, Christianson MD, Jacobsen G, Hirsch JD, Reis BL. Reliability and validity of the ocular surface disease index. Arch Ophthalmol. 2000:118:615-21.

43. Begley CG, Chalmers RL, Abetz L, Venkataraman K, Mertzanis P, Caffery BA, et al. The relationship between habitual patient-reported symptoms and clinical signs among patients with dry eye of varying severity. Invest Ophthalmol Vis Sci. 2003:44:4753-61.

44. Sullivan BD, Crews LA, Messmer EM, Foulks GN, Nichols KK, Baenninger P, et al. Correlations between commonly used objective signs and symptoms for the diagnosis of dry eye disease: clinical implications. Acta Ophthalmol. 2014:92:161-6.

45. Bron AJ, Evans VE, Smith JA. Grading of corneal and conjunctival staining in the context of other dry eye tests. Cornea. 2003;22:640-50.

46. Nichols KK, Nichols JJ, Mitchell GL. The lack of association between signs and symptoms in patients with dry eye disease. Cornea. 2004;23:762-70.

47. Kanellopoulos AJ, Asimellis G. In vivo 3-dimensional corneal epithelial thickness mapping as an indicator of dry Eye: preliminary clinical assessment. Am J Ophthalmol. 2014:157:63-8.e2.

48. Hutchings N, Simpson TL, Hyun C, Moayed AA, Hariri S, Sorbara L, et al. Swelling of the human cornea revealed by high-speed, ultrahigh-resolution optical coherence tomography. Invest Ophthalmol Vis Sci. 2010;51:4579-84.

49. Hong J, Qian T, Yang Y, Jiang C, Liu Z, Sun $X$, et al. Corneal epithelial thickness map in long-term soft contact lenses wearers. Optom Vis Sci. 2014:91:1455-61.

50. Haque S, Fonn D, Simpson T, Jones L. Epithelial thickness changes from the induction of myopia with CRTH RGP contact lenses. Invest Ophthalmol Vis Sci. 2008:49:3345-50 
51. Kanellopoulos AJ, Asimellis G. Anterior segment optical coherence tomography: assisted topographic corneal epithelial thickness distribution imaging of a keratoconus patient. Case Rep Ophthalmol. 2013;4:74-8.

52. Kanellopoulos AJ, Aslanides IM, Asimellis G. Correlation between epithelial thickness in normal corneas, untreated ectatic corneas, and ectatic corneas previously treated with $C X L$; is overall epithelial thickness a very early ectasia prognostic factor? Clin Ophthalmol. 2012;6:789-800.

53. Kanellopoulos AJ, Asimellis G. Corneal epithelial remodeling following cataract surgery: three-dimensional investigation with anterior-segment optical coherence tomography. J Refract Surg. 2014;30:348-53.

54. Kanellopoulos AJ, Asimellis G. Anterior-segment optical coherence tomography investigation of corneal deturgescence and epithelial remodeling after DSAEK. Cornea. 2014;33:340-8.

55. Kanellopoulos AJ, Asimellis G. Longitudinal postoperative lasik epithelial thickness profile changes in correlation with degree of myopia correction. J Refract Surg. 2014;30:166-71.

56. Kanellopoulos AJ, Asimellis G. Epithelial remodeling after femtosecond laserassisted high myopic LASIK: comparison of stand-alone with LASIK combined with prophylactic high-fluence cross-linking. Cornea. 2014;33:463-9.

57. Rodriguez JD, Ousler GW, Johnston PR, Lane K, Abelson MB. Investigation of extended blinks and interblink intervals in subjects with and without dry eye. Clin Ophthalmol. 2013;7:337-42.

58. Francoz M, Karamoko I, Baudouin C, Labbé A. Ocular surface epithelial thickness evaluation with spectral-domain optical coherence tomography. Invest Ophthalmol Vis Sci. 2011;52:9116-23.

59. Fabiani C, Barabino S, Rashid S, Dana MR. Corneal epithelial proliferation and thickness in a mouse model of dry eye. Exp Eye Res. 2009:89:166-71.

60. Hu Y, Matsumoto Y, Adan ES, Dogru M, Fukagawa K, Tsubota K, et al. Corneal in vivo confocal scanning laser microscopy in patients with atopic keratoconjunctivitis. Ophthalmology. 2008;115:2004-12.

61. Erdelyi B, Kraak R, Zhivov A, Guthoff R, Németh J. In vivo confocal laser scanning microscopy of the cornea in dry eye. Graefes Arch Clin Exp Ophthalmol. 2007;245:39-44.

62. Tuominen IS, Konttinen YT, Vesaluoma MH, Moilanen JA, Helintö M, Tervo TM. Corneal innervation and morphology in primary Sjögren's syndrome. Invest Ophthalmol Vis Sci. 2003;44:2545-9.

63. McLaren JW, Nau CB, Erie JC, Bourne WM. Corneal thickness measurement by confocal microscopy, ultrasound, and scanning slit methods. Am J Ophthalmol. 2004;137:1011-20.

64. Erdélyi B, Kraak R, Zhivov A, Guthoff R, Németh J. In vivo confocal lase scanning microscopy of the cornea in dry eye. Graefes Arch Clin Exp Ophthalmol. 2007;245:39-44

65. Li HF, Petroll WM, Moller-Pedersen T, Maurer JK, Cavanagh HD, Jester JV. Epithelial and corneal thickness measurements by in vivo confocal microscopy through focusing (CMTF). Curr Eye Res. 1997;16:214-21.

66. Tao A, Shao $Y$, Jiang $H$, Ye Y, Lu F, Shen M, et al. Entire thickness profiles of the epithelium and contact lens in vivo imaged with high-speed and highresolution optical coherence tomography. Eye Contact Lens. 2013;39:329-34.

67. Li Y, Tan O, Brass R, Weiss JL, Huang D. Corneal epithelial thickness mapping by fourier-domain optical coherence tomography in normal and keratoconic eyes. Ophthalmology. 2012;119:2425-33.

68. Wirbelauer C, Pharo DT. Monitoring corneal structures with slitlamp-adapted optical coherence tomography in laser in situ keratomileusis. J Cataract Refract Surg. 2004;30:1851-60.

69. Haque S, Simpson T, Jones L. Corneal and epithelial thickness in keratoconus: a comparison of ultrasonic pachymetry, Orbscan II, and optical coherence tomography. J Refract Surg. 2006;22:486-93.

70. Rocha KM, Perez-Straziota E, Stulting RD, Randleman JB. SD-OCT analysis of regional epithelial thickness profiles in keratoconus, postoperative corneal ectasia, and normal eyes. J Refract Surg. 2013;29:173-9.

71. Kanellopoulos AJ, Asimellis G. In vivo three-dimensional corneal epithelium imaging in normal eyes by anterior segment optical coherence tomography: a clinical reference study. Cornea. 2013;32:1493-8.

72. Wu S, Tao A, Jiang H, Xu Z, Perez V, Wang J. Vertical and horizontal corneal epithelial thickness profile using ultra-high resolution and long scan depth optical coherence tomography. PLoS One. 2014;9:e97962.

73. Zhou W, Stojanovic A. Comparison of corneal epithelial and stromal thickness distributions between eyes with keratoconus and healthy eyes with corneal astigmatism $\geq 2.0$ D. PLoS One. 2014;9:e85994.
74. Cui X, Hong J, Wang F, Deng SX, Yang Y, Zhu X, et al. Assessment of corneal epithelial thickness in dry eye patients. Optom Vis Sci. 2014;91:1446-54.

75. Hori J, Joyce NC, Streilein JW. I Immune privilege and immunogenicity reside among different layers of the mouse cornea. 2000. Ocul Immunol Inflamm. 2007;15:225-39.

76. Kanellopoulos AJ, Asimellis G. Reply: To PMID 24200234. Am J Ophthalmol. 2014;157(5):1116-7.

77. Sullivan BD, Whitmer D, Nichols KK, Tomlinson A, Foulks GN, Geerling G, et al. An objective approach to dry eye disease severity. Invest Ophthalmol Vis Sci. 2010;51:6125-30

78. Kamao T, Yamaguchi M, Kawasaki S, Mizoue S, Shiraishi A, Ohashi Y. Screening for dry eye with newly developed ocular surface thermographer. Am J Ophthalmol. 2011;151:782-91.

79. Hong J, Sun X, Wei A, Cui X, Li Y, Qian T, et al. Assessment of tear film stability in dry eye with a newly developed keratograph. Cornea. 2013;32:716-21.

80. Bourcier T, Acosta MC, Borderie V, Borrás F, Gallar J, Bury T, et al. Decreased corneal sensitivity in patients with dry eye. Invest Ophthalmol Vis Sci. 2005;46(7):2341-5.

81. De Paiva CS, Pflugfelder SC. Corneal epitheliopathy of dry eye induces hyperesthesia to mechanical air jet stimulation. Am J Ophthalmol. 2004;137(1):109-15.

\section{Submit your next manuscript to BioMed Central and we will help you at every step:}

- We accept pre-submission inquiries

- Our selector tool helps you to find the most relevant journal

- We provide round the clock customer support

- Convenient online submission

- Thorough peer review

- Inclusion in PubMed and all major indexing services

- Maximum visibility for your research

Submit your manuscript at www.biomedcentral.com/submit
) Biomed Central 